\title{
Calculation Method for Load-Carrying Capacity of Circular Reinforced Con
}

\author{
Tingwei Wang * \\ State Nuclear Electric Power Planning, Design \& Research Institute CO., LTD., Beijing, China
}

\begin{abstract}
Finite element method and fiber model method were used to calculate the load-carrying capacity of the specimens. Based on the experimental and theoretical analysis, simplified calculation method of the load-carrying capacity for this kind of member is proposed. It indicates that finite element method result is relatively small, fiber model method result accords well with the experimental result. Circular reinforced concrete members covered with steel tube presents both the characteristics of reinforced concrete and concrete filled steel tube member, showing higher load-carrying capacity and greater deformability. The load-carrying capacity of circular reinforced concrete members covered with steel tube can be calculated by the means of the method of reinforced concrete member with confined concrete. The result predicted by the simplified method is in good agreement with the experimental result.
\end{abstract}

Keywords: Reinforced concrete members covered with steel tube; circular section; load-carrying capacity.

\section{Preface}

In the $1990 \mathrm{~s}$, rock-socketed pile, as a specific pile foundation type, has been widely used in China, and is now more and more widely used in port engineering and bridge engineering. In order to reduce the number of piles, large diameter rock-socketed piles are mostly used. Large diameter rock-socketed piles have the advantages of high bearing capacity, large pile diameter, small settlement and good seismic performance. In the process of pile driving, in order to prevent the steel sleeve from rim and warping, a steel sleeve with a large thickness is generally used, but the thick sleeve wall increases the cost of the project. For example, in the wharf project of Yantian Port in Shenzhen and the wharf project of Huaneng Fuzhou Power Plant, the wall thickness of the steel sleeve of rock-socketed pile can be up to $20 \mathrm{~mm}$. In the bearing capacity design of rocksocketed pile, due to the lack of theoretical guidance and calculation formula, the bearing capacity of steel sleeve is generally ignored at present, and only the bearing capacity of reinforced concrete pile is considered. In fact, the steel sleeve and the reinforced concrete in the pile bear the load together, even if a certain part of the steel sleeve is corroded, but the remaining part still has a large bearing capacity. Therefore, if the effect of sleeve is considered in the design, the number of reinforcement in the pile can be reduced and the project cost can be greatly reduced. The member composed of steel sleeve and reinforced concrete in pile is steel tubular reinforced concrete member. There are relevant standards and design specifications for CFST and $\mathrm{RC}$, but there is no calculation method for the bearing capacity of CFST members. At present, there are few researches on the bearing capacity of CFST members. Some existing researches [1-6] mainly focus on the axial compression performance of CFST members. The research on eccentric compression behavior of steel tubular reinforced concrete members is lacking. Based on the experimental study and theoretical analysis of 8 circular section steel tube reinforced concrete (CFST) specimens, a calculation method for the bearing capacity of CFST members is proposed in this paper.

\section{Theoretical Analysis}

\subsection{Theoretical analysis methods}

In this paper, three methods are used to calculate the bearing capacity of steel tubular reinforced concrete members. The material constitutive model, strength model and parameters used in the specific method and analysis are as follows.

\footnotetext{
* Corresponding author: wangtingwei@snpdri.com
} 


\subsubsection{Finite element method}

The finite element method used Abaqus software, steel and rebar used the isotropic elastic-plastic model provided by Abaqus software, and concrete used the plastic damage model provided by Abaqus software.

\subsubsection{Fiber model method}

The fiber model method can accurately simulate the process from loading to failure of reinforced concrete members and concrete-filled steel tubular members, and the key is to reasonably determine the constitutive relations of each material.

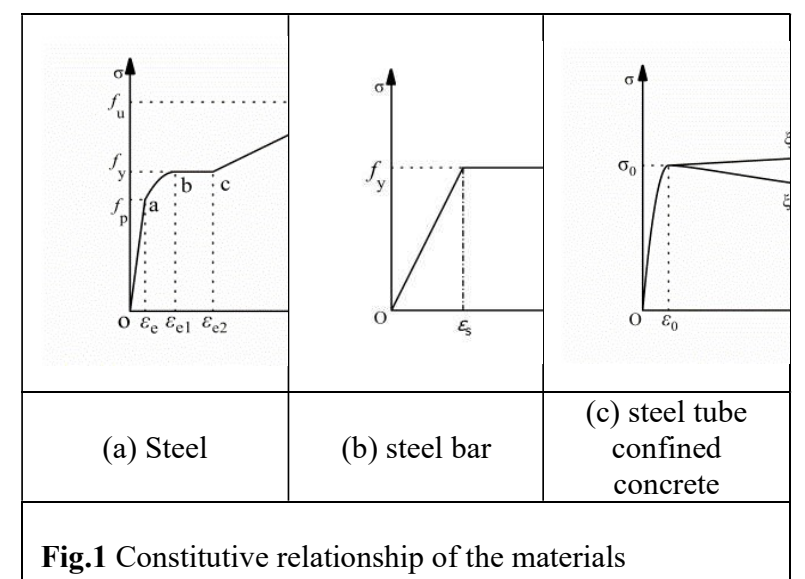

The steel adopts the stress-strain relationship expressed in the following formula, as shown in FIG. 1(a) [7] :

$$
\sigma_{s t}=\left\{\begin{array}{cc}
E_{s} \varepsilon_{s} & \left(\varepsilon_{s} \leq \varepsilon_{e}\right) \\
-A \varepsilon_{s}^{2}+B \varepsilon_{s}+C & \left(\varepsilon_{e}<\varepsilon_{s} \leq \varepsilon_{e 1}\right) \\
f_{y t} & \left(\varepsilon_{e 1}<\varepsilon_{s} \leq \varepsilon_{e 2}\right) \\
f_{y t}\left(1+0.6 \frac{\varepsilon_{s}-\varepsilon_{e 2}}{\varepsilon_{e 3}-\varepsilon_{e 2}}\right) & \left(\varepsilon_{e 2}<\varepsilon_{s} \leq \varepsilon_{e 3}\right) \\
1.6 f_{y t} & \left(\varepsilon_{e 3}<\varepsilon_{s}\right)
\end{array}\right.
$$

In

$$
\begin{gathered}
A=0.2 f_{y t} /\left(\varepsilon_{e 1}-\varepsilon_{e}\right)^{2}, B=2 A \varepsilon_{e 1}, \\
C=0.8 f_{y t}+A \varepsilon_{e}^{2}-B \varepsilon_{e}
\end{gathered}
$$

Where, $\sigma_{s}$ is steel stress; $E_{s}$ is the elastic modulus of steel, take $206000 \mathrm{MPa} ; \varepsilon_{s}$ is steel strain; $\varepsilon_{\varepsilon}$ is the strain corresponding to the limit of steel proportion, $\varepsilon_{e}=0.8 f_{y} / E_{s} . \varepsilon_{\mathrm{e} 1}$ is the strain corresponding to the yield limit of steel, $\varepsilon_{e 1}=1.5 \varepsilon_{e} ; \varepsilon_{\mathrm{e} 2}$ is the strain corresponding to the end point of the plastic section of the steel stress-strain curve, $\varepsilon_{e 2}=10 \varepsilon_{e 1} ; \varepsilon_{\mathrm{e} 3}$ is the strain corresponding to the ultimate tensile strength of steel, $\varepsilon_{e 3}=100 \varepsilon_{e 1}$.

The stress-strain relationship of rebar adopts the linearcomplete plastic model [8], as shown in FIG. 1(b), namely:

$$
\sigma_{s}=\left\{\begin{aligned}
E_{s} \varepsilon_{s} & \left(0<\varepsilon_{s} \leq \varepsilon_{y}\right) \\
f_{y} & \left(\varepsilon_{y}<\varepsilon_{s}\right)
\end{aligned}\right.
$$

Where, $\varepsilon_{\mathrm{s}}$ is the reinforcement strain; $\varepsilon_{y}$ is the yield strain of reinforcement, $\varepsilon_{y}=f_{y} / E_{s} ; E_{s}$ is the elastic modulus of the steel bar, which is $200000 \mathrm{MPa}$.

The stress-strain relationship model of circular concretefilled steel tube core concrete in literature [7] is adopted for concrete, as shown in FIG. 5(c), namely:

$$
\begin{aligned}
& y=2 x-x^{2} \quad(x \leq 1) \\
& y=\left\{\begin{array}{lc}
1+q \cdot\left(x^{0.1 \xi}-1\right) & (\xi \geq 1.12) \\
\frac{x}{\beta(x-1)^{2}+x} & (\xi<1.12)
\end{array} \quad(x>1)(3)\right. \\
& x=\frac{\varepsilon}{\varepsilon_{0}}, y=\frac{\sigma}{\sigma_{0}}, \xi=\frac{A_{\mathrm{st}} f_{\mathrm{yt}}}{A_{\mathrm{c}} f_{\mathrm{ck}}}
\end{aligned}
$$$$
\text { In }
$$

Where, $\sigma, \varepsilon$ are compressive stress and compressive strain of concrete; $\sigma_{0}, \varepsilon_{0}$ is peak compressive stress and peak compressive strain of concrete; $\xi$ is the constraint effect coefficient of CFST; $f_{\mathrm{yt}}, A_{\mathrm{st}}$ is the yield strength and sectional area of steel pipe; $f_{\mathrm{ck}} 、 A_{\mathrm{c}}$ are the standard compressive strength and sectional area of concrete.

The fiber model method considers the stress on steel pipe and the constraint effect on concrete separately, which belongs to one-dimensional stress analysis considering transverse constraint. Compared with the finite element method (three-dimensional stress analysis), the calculation is simple. 


\subsubsection{Simplified calculation method}

The above two methods are suitable for the study of loaddeformation process and stress mechanism of steel tubular reinforced concrete members, but they are not convenient for engineering design because of the complexity of calculation. Therefore, a simplified bearing capacity calculation method suitable for engineering application should be studied. Although there are special design codes for reinforced concrete and concrete filled steel tube, the methods in these codes cannot be directly used to calculate the bearing capacity of reinforced concrete filled steel tube. Considering that steel casing is usually neglected in the design of rock-socketed piles in the past, the calculation method of the bearing capacity of steel tubular reinforced concrete members is more appropriate. Code for Design of Concrete Structures in Water Transport Engineering (JTS 151-2011[9]) gives the calculation method of the bearing capacity of circular section reinforced concrete members. The formula is simplified on the basis of theoretical analysis, that is, when there are no less than 6 steel bars uniformly distributed along the circumference, the steel bars are continuously converted into steel rings with the same area. For the circular section steel tube reinforced concrete member, different from the ordinary reinforced concrete member, the concrete is constrained by the steel pipe, and the steel pipe also directly participates in the force. Therefore, in theory, steel pipe can be regarded as reinforcing steel, while concrete can be regarded as restrained concrete. In other words, the simplified steel tubular reinforced concrete is considered as double steel bars, and the concrete is calculated according to the strength of constrained concrete. The calculation formula is:

$$
\begin{gathered}
N_{u}=\alpha \alpha_{1} f_{c c} A_{c}\left(1-\frac{\sin 2 \pi \alpha}{2 \pi \alpha}\right)+\left(\alpha-\alpha_{t}\right)\left(f_{y} A_{s}+f_{y t} A_{s t}\right) \\
M_{u}=\eta N_{u} e_{i}=\frac{2}{3} \alpha_{1} f_{f_{c}} A_{c t} r_{c} \frac{\sin ^{3} \pi \alpha}{\pi}+\left(f_{y} A_{s} r_{s}+f_{y} A_{y s} r_{s t}\right)\left(\frac{\sin \pi \alpha+\sin \pi \alpha_{t}}{\pi}\right) \\
\alpha_{t}=1.25-2 \alpha, e_{i}=e_{0}+e_{a}
\end{gathered}
$$

Where, $N_{u} 、 M_{u}$ are the allowable axial force and bending moment of steel tubular reinforced concrete members; $f_{c c}$ is the strength of steel tube confined concrete, calculated according to the following formula:

$$
f_{c c}=\left[1+\left(-0.054 \cdot \xi^{2}+0.4 \cdot \xi\right) \cdot\left(\frac{24}{f_{c}}\right)^{0.45}\right] f_{c}
$$

$f_{c}$ is the axial compressive strength of concrete; $f_{y}$ 、 $A_{s} 、 r_{s}$ is the yield strength, sectional area and radius of the circumference of the reinforcement; $f_{y t} 、 A_{s t}, r_{s t}$ are the yield strength, sectional area and radius of the circumference of the steel pipe; $e_{0} 、 e_{a}, \eta$ Is the initial eccentricity, additional eccentricity and eccentricity increase coefficient of components, which are determined according to Code for Concrete Structure Design of Water Transport Engineering (JTS 151-2011) [9].

For the case of axial compression, formula (4) is changed by referring to reference [9]

$$
N_{u}=0.9 \varphi\left(f_{c c} A_{c}+f_{y} A_{s}+f_{y t} A_{s t}\right)
$$

Where, $\varphi$ is the stability coefficient, and is valued according to literature [9].

\section{Conclusion}

In this paper, the experimental research and theoretical analysis of the bearing capacity of circular section steel tube reinforced concrete members are carried out. The study concluded as follows:

(1) When calculating the bearing capacity of the circular section steel tubular reinforced concrete member, the circular section steel tubular reinforced concrete member can be equivalent to the double layer reinforced concrete member for calculation.

(2) The double-layer reinforcement constraint can delay the failure of the core concrete and make the steel tubular reinforced concrete members show high deformation capacity.

(3) The simplified calculation method of the bearing capacity of circular section steel tube reinforced concrete members proposed in this paper has simple calculation and high precision, which is suitable for engineering application.

\section{References}

1. SHU Gan-ping, LIU Xiao-ying, MIAO Wei. Experimental research and bearing capacity analysis of axial compressive reinforced concrete-filled steel tube short column[J]. Industrial construction, 2010, 40(4): 100-106. (in Chinese)

2. HAN Jin-sheng, DONG Yu-li, XU Zhao-dong et,al. Analysis of axial compression performance for reinforced concrete-filled tubular steel[J].Journal of Civil, Architectural \& Environmental Engineering , 2009, 31(3): 11-17.(in Chinese)

3. HOU Yu-ying. Mechanical analysis of reinforced concrete-filled steel tube[J]. Architecture Design Management, 2010, 27(12): 46-48.(in Chinese)

4. LIU Zhao, ZHAO Jun-hai, WANG Juan et,al. Analysis of axial bearing capacity of reinforced concrete-filled circular steel tube short columns[J]. Journal of Architecture and civil Engineering, 2011, 28(4): 92-96.(in Chinese)

5. WEI Hua, WANG Hai-jun. Investigation on strength of concrete-filled circular steel tubular columns[J].Journal of Harbin Institute Technology, 2007, 39(2): 70-73. (in Chinese)

6. WANG Wei, QU Wei-lian. State of the art of elasticplastic ultimate loads of concrete filled steel tube[J]. 
J. of HU ST.(Urban Science Edit ion) , 2004, (2): 4446.(in Chinese)

7. HAN Lin-hai. Structure of concrete filled steel tube Theory and Practice [M]. Beijing: Science Press, 2004.(in Chinese)

8. GB50017-2017, Code for design of steel structures[S]. (in Chinese)

9. JTS 151-2011, Design code for concrete structures of port and waterway engineering[S]. (in Chinese) 